\title{
Respostas fisiológicas em mudas de bananeira tratadas com estrobilurinas
}

\section{Physiological responses in the banana plantlets treateds with strobilurins}

\author{
Juliana Domingues Lima ${ }^{1 *}$; Wilson da Silva Moraes ${ }^{2}$; \\ Silvia Helena Modenese-Gorla da Silva ${ }^{1}$
}

\begin{abstract}
Resumo
Há relatos de que estrobilurinas, além de atuarem como fungicida, promovem benefícios fisiológicos às plantas. Assim sendo, o presente trabalho teve como objetivo avaliar o efeito de estrobirulinas na fisiologia de mudas de bananeira. Para tal, mudas micropropagadas da cultivar Grand Naine foram repicadas para vasos contendo substrato e mantidas em viveiro a $50 \%$ de sombreamento. O delineamento experimental foi inteiramente casualizado, com três tratamentos (água, azoxistrobina e piraclostrobina) e cinco repetições. As estrobirulinas foram aplicadas com pulverizador manual aos 15, 30, 45, 60 e 75 dias após a repicagem, na dose de $100 \mathrm{~g}$ i. a. ha ${ }^{-1}$. A altura da planta, diâmetro do pseudocaule e a massa da matéria seca da parte aérea de plantas tratadas com estrobilurinas foram superiores às de plantas não tratadas. O efeito do tratamento com fungicidas foi diferenciado, sendo mais pronunciado nas plantas tratadas com piraclostrobina do que nas plantas tratadas com azoxistrobina. Plantas tratadas com piraclostrobina apresentaram área foliar, atividade da redutase do nitrato e teor de clorofila $a$ e de nitrogênio total foliar superiores às plantas tratadas com azoxistrobina e água, que não diferiram entre si. As estrobilurinas afetaram a fisiologia das mudas de bananeira, com destaque para a piraclostrobina. Palavras-chave: Musa sp., efeito fisiológico, azoxistrobina, piraclostrobina
\end{abstract}

\begin{abstract}
There are reports that strobilurin besides having a fungicide effect can promote physiologic benefits to the plants. However, this effect on banana plants was not studied yet. The objective of the present study was to evaluate the effect of strobirulins on the physiology of banana plantlets. For this purpose, cultivar Grand Naine banana plantlets were transferred to pots containing substrate and kept in a nursery with $50 \%$ shading. The experimental design was a completely randomized design with three treatments (water, azoxystrobin and pyraclostrobin) and five replications. The treatments were applied at 15, 30, 45, 60 and 75 days after transplanting at a dose $100 \mathrm{~g}$ a. i. ha ${ }^{-1}$ with manual spray. Plant height, pseudostem diameter, shoot dry matter in strobilurin treated plants were higher than the untreated plants, however, the effect of fungicide treatment was different, being the most pronounced effect of pyraclostrobin compared to azoxystrobin. Plants treated with pyraclostrobin had higher leaf area, nitrate reductase activity and chlorophyll content of leaf total nitrogen than the plants treated with azoxystrobin and water, which did not differ. Strobilurins affect the physiology of the banana plantlets differently, the effect being more pronounced by pyraclostrobin.
\end{abstract}

Key words: Musa sp., physiological effect, fungicide, azoxystrobin, piraclostrobin

1 Profs. da Universidade Estadual Paulista "Júlio de Mesquita Filho", UNESP, Campus Experimental de Registro. Registro, SP. E-mail: judlima@registro.unesp.br; silvia@registro.unesp.br

2 Pesquisador da Agência Paulista de Tecnologia dos Agronegócios, APTA, Pólo Regional Vale do Ribeira. Registro, SP. E-mail: wilson@apta.sp.gov.br

Autor para correspondência 


\section{Introdução}

No Brasil, a produção de banana ocorre em todos os estados, ocupando área de cerca de 490 mil hectares com produção estimada em 7 milhões de toneladas (IBGE, 2011). Apesar da produção nacional ser relativamente grande, colocando o Brasil na quarta posição em termos mundial, ainda predominam baixos índices de produtividade e qualidade do fruto (NÓBREGA et al., 2010). Um dos fatores que contribuem para esse quadro é o controle fitossanitário inadequado.

Quando se utilizam variedades de bananeira suscetíveis à Sigatoka-Negra e Sigatoka-Amarela, principais doenças foliares da bananeira (MORAES et al., 2006), as estratégias para o controle baseiamse em práticas culturais e no emprego de fungicidas (CORDEIRO; MATOS; MEISSNER FILHO, 2004). Dentre os fungicidas sistêmicos recomendados destacam-se aqueles pertencentes aos diferentes grupos químicos com diferentes mecanismos de ação, tais como, os benzimidazóis, que bloqueiam a síntese de RNA, os triazóis, que inibem da biossíntese de ergosterol, e as estrobilurinas, que bloqueiam a respiração mitocondrial (MORAES et al., 2006).

As propriedades das estrobirulinas foram intensamente estudadas na última década na tentativa de comprovar evidências de sua influência direta em processos fisiológicos de plantas não infectadas ou ameaçadas por patógenos. Essa atividade denominada de "efeito fisiológico" (VENÂNCIO et al., 2003) foi comprovada em diversos estudos por meio do aumento da massa da matéria seca, conteúdo de clorofilas e proteínas, além do atraso na senescência (YPEMA; GOLD, 1999; MERCER; RUDDOCK, 1998), o que na maioria das vezes resultou no aumento da produtividade (GROSSMAN; RETZLAFF, 1997; JONES; BRYSON, 1998; DOURADO NETO; OLIVEIRA, 2005; BERTELSEN; NEERGAARD; SMEDEGAARD-PETERSEN, 2001; FAGAN et al., 2010). Até recentemente, o uso de fungicidas no manejo fitossanitário tinha como único foco o controle de doenças, passando agora a ter uma perspectiva ampliada devido aos benefícios fisiológicos.

O maior conteúdo de clorofilas e proteínas é atribuído a maior assimilação de nitrogênio (YPEMA; GOLD, 1999; MERCER; RUDDOCK, 1998) que requer, como passo inicial, a ação da enzima redutase do nitrato, que por sua vez catalisa a transformação do nitrato em nitrito em uma velocidade limitante, refletindo em todo o processo de assimilação do nitrato (LEA, 1997). Sendo assim, essa reação é considerada um alvo relevante na produção vegetal induzida pela estrobilurina (KÖEHLE et al., 2003). O atraso na senescência em plantas tratadas com estrobilurinas foi atribuído ao decréscimo na produção de etileno (GROSSMAN; RETZLAFF, 1997), que como conseqüência promove degradação mais lenta das citocininas (BOLLMARK; ELIASSON, 1990). Todavia, Wu e Tiedemann (2001) relacionaram o atraso na senescência em plantas de trigo a uma maior eficiência do sistema antioxidante que protege as plantas de espécies ativas de oxigênio prejudiciais. Assim, a redução na síntese de etileno pode não ser o principal mecanismo pelo qual estrobilurinas interferirem no processo de senescência. Em outras espécies vegetais, como soja (AUGUSTI et al., 2010; FAGAN et al., 2010; TSUMANUMA et al., 2010; BALARDIN et al., 2011), batata (LOPES, 2011), pepino (AMARO, 2011) também foram observados efeitos fisiológicos benéficos após o tratamento com estrobilurinas.

Pelo exposto, o presente trabalho teve como objetivo avaliar o efeito de estrobirulinas na fisiologia de mudas de bananeira.

\section{Material e Métodos}

Os ensaios foram realizados no Câmpus Experimental de Registro, UNESP, utilizando-se mudas da cultivar Grand Naine, micropropagadas no Laboratório da Agência Paulista de Tecnologia 
dos Agronegócios - APTA, Pólo Regional do Vale do Ribeira, em Pariquera-Açu, SP.

Na ocasião da repicagem, as mudas apresentavam cerca de cinco centímetros de altura, quatro a cinco folhas e raiz nua, sendo plantadas em vasos contendo dois litros de substrato composto de terra de subsolo, Rendimax Floreira ${ }^{\circledR}$ e casca de arroz carbonizada na proporção 1:1:1 (v/v/v). Os vasos foram dispostos sobre bancada, mantendo-se o espaçamento de $20 \mathrm{~cm}$ entre os mesmos. Irrigações foram realizadas diariamente, elevando-se o nível de água do substrato até a capacidade de campo. Trinta dias após a repicagem aplicou-se em cobertura o fertilizante formulado NPK granulado, 10-10-10 na dose de $10 \mathrm{~g} \mathrm{muda}^{-1}$.

O delineamento experimental foi inteiramente casualizado, com três tratamentos (água, azoxistrobina e piraclostrobina) e cinco repetições, sendo uma planta por parcela. Os produtos comerciais Comet e Priori foram utilizados como fonte de azoxistrobina e piraclostrobina, respectivamente, sendo aplicados na dose recomendada pelo fabricante (100 g i. a. ha-1), aos 15, 30, 45, 60 e 75 dias após a repicagem. As aplicações foram realizadas distribuindo-se cerca de $10 \mathrm{~mL}$ da calda do fungicida por planta utilizando um pulverizador manual.

Em cinco plantas de cada tratamento, aos 16, 31, 46, 61 e 76 dias após a repicagem, ou seja, 24 horas após aplicação dos fungicidas, foram determinados a atividade da enzima redutase do nitrato (RN; EC 1.6.6.1) e o teor de aminoácidos livres totais no tecido foliar. Aos 84 dias após da repicagem, em outras cinco plantas de cada tratamento, foram determinadas a altura, diâmetro do pseudocaule, número de folhas, área foliar, massa da matéria seca da parte aérea e da raiz, teor de pigmentos fotossintéticos e o nitrogênio total das folhas.

Para determinação da atividade da redutase do nitrato, foram coletados $0,25 \mathrm{~g}$ de material vegetal do limbo da última folha completamente expandida da planta, sempre às 10 horas da manhã.
A metodologia utilizada foi a proposta por Jaworski (1971), segundo a qual a quantidade de nitrito liberada por fragmentos de tecidos vivos num tampão, na presença de um agente permanente (propanol) e do substrato (nitrato), reflete a atividade potencial da $\mathrm{RN}$ in vivo (HAGEMAN; REED, 1980). Em estudos preliminares, foram determinadas as condições ótimas de $\mathrm{pH}$, temperatura, concentração de nitrato, bem como o tempo de incubação mais adequado para o tecido foliar de bananeira (VAZAMI et al., 2007). Assim, o meio de incubação utilizado foi 0,1 M tampão de fosfato de potássio $\mathrm{pH} 7,5,1 \%$ de N-propanol (v/v), $100 \mathrm{mmol} \mathrm{L}^{-1}$ de nitrato. A incubação foi conduzida a $30{ }^{\circ} \mathrm{C}$ por 1 hora no escuro. Decorrido o tempo de incubação, foram retiradas alíquotas do meio de ensaio, passadas por filtros de microfibra de vidro, a fim de retirar o material vegetal. Na seqüência 1 $\mathrm{mL}$ do filtrado obtido colocado em tubo de ensaio contendo $1 \mathrm{~mL}$ de sulfanilamida $1 \%$ em $\mathrm{HCl} 3 \mathrm{~N}$ para que a atividade enzimática fosse paralisada. A mistura foi agitada, filtrada, colocada em repouso por 30 minutos, lida a absorvância a $540 \mathrm{~nm} \mathrm{e}$ expressa em $\mu$ mol $\mathrm{NO}_{2}^{-1} \mathrm{~g}^{-1}$ de matéria fresca $\mathrm{h}^{-1}$. A leitura foi feita em espectrofotômetro a $540 \mathrm{~nm}$, sendo a atividade da enzima determinada pela quantidade de nitrito produzido, comparando os valores obtidos com a curva padrão de nitrito, em quantidades variando de 50 a $500 \mathrm{nmol}$ de nitrito.

Para determinação do teor de aminoácidos livres totais, uma porção do limbo foliar coletada foi macerada em MCW (metanol:clorofórmio:água), na proporção de 12:5:3 (BIELESKI; TURNER, 1966). Posteriormente, foram feitas três extrações intercaladas por centrifugações a $4000 \mathrm{~g}$ (1ª: $20 \mathrm{~min}$, 2a 10 min e $3^{\text {a }}$ : 10 min), e os sobrenadantes de cada uma das centrifugações reunidos. Para cada $4 \mathrm{~mL}$ do extrato adicionou-se 1,0 $\mathrm{mL}$ de clorofórmio e 1,5 $\mathrm{mL}$ de água deionizada. Após intensa agitação, fezse a centrifugação da mistura a $2000 \mathrm{~g}$ por $10 \mathrm{~min}$, para acelerar a separação das fases. Com auxílio de uma pipeta Pasteur, a fração aquosa-metanólica foi retirada e submetida ao banho-maria a $40^{\circ} \mathrm{C}$, durante 
2 horas, para completa eliminação do resíduo de clorofórmio. Finalmente, determinou-se o volume final em proveta. A partir desta solução, os teores de aminoácidos livres totais foram determinados, adotando-se o procedimento proposto por Yemm e Cocking (1955). Para tal, foi colocado $1 \mathrm{~mL}$ do extrato, adequadamente diluído com água ou do padrão leucina (0-200 nmol), em tubos de ensaio e adicionado $0,5 \mathrm{~mL}$ de tampão citrato $0,2 \mathrm{M} \mathrm{pH}$ $5,0,0,2 \mathrm{~mL}$ do reativo de ninhidrina $5 \%$ em metilcelosolve (éter monometílico de etilenoglicol), mais $1 \mathrm{~mL}$ de $\mathrm{KCN} 2 \%$ (v/v) em metil-celosolve, sendo a solução de KCN preparada em água, a partir de uma solução 0,01 M de KCN. Os tubos de ensaio foram cobertos e colocados em banho-maria a $100{ }^{\circ} \mathrm{C}$ por 20 min. Em seguida, os tubos foram transferidos para o escuro à temperatura ambiente, acrescentado $1,3 \mathrm{~mL}$ de etanol $60 \%(\mathrm{v} / \mathrm{v})$ e submetidos à agitação. Após 5 min, a absorbância do padrão, das amostras e do extrato foram medidas a $570 \mathrm{~nm}$.

A área foliar foi determinada por meio do integralizador de área portátil Licor modelo LI 3000 e a massa da matéria seca foi obtida após a secagem em estufa a $70^{\circ} \mathrm{C}$, até massa constante. A extração de pigmentos fotossintéticos foi feita segundo metodologia de Hiscox e Israelstam (1979), sendo os teores de clorofila $a$ e $b$ e carotenóides determinados por equações propostas por Wellburn (1994). O teor de nitrogênio total foi determinado em amostra do tecido foliar, após a determinação da massa da matéria seca em estufa a $70^{\circ} \mathrm{C}$, no laboratório da Faculdade de Ciências Agrárias de Botucatu.

Os resultados apresentados representam a média de dois experimentos. A análise estatística foi realizada no programa estatístico Sisvar 4.2, desenvolvido no Departamento de Ciências Exatas, da Universidade Federal de Lavras, MG (UFLA). Os dados foram submetidos aos testes de normalidade (teste de Lilliefors) e homogeneidade (teste de Cochran) e evidenciaram ser desnecessária a realização de transformação. Os dados foram então submetidos à análise de variância, por meio do teste $\mathrm{F}$, sendo as médias dos tratamentos comparadas pelo teste Tukey $(\mathrm{p}<0,05)$. Os dados também foram submetidos à análise da regressão, a fim de estudar o incremento de algumas variáveis em função das épocas de avaliação, sendo a escolha do modelo baseada na significância do coeficiente de determinação obtido pelo teste $\mathrm{t}$.

\section{Resultados e Discussão}

Aos 84 dias após a repicagem, as plantas tratadas com estroubirulinas apresentaram maior altura, diâmetro do pseudocaule e massa da matéria seca da parte aérea quando comparadas com plantas não-tratadas, sendo o efeito de piraclostrobina mais pronunciado quando comparado com azoxistrobina (Tabela 1). Plantas tratadas com piraclostrobina apresentaram também área foliar e teor de nitrogênio total foliar superiores às plantas tratadas com azoxistrobina e água, que não diferiram entre si. Apesar das alterações no crescimento e acúmulo de matéria seca, os teores de clorofilas $b$ e carotenóides não foram alterados com a aplicação de estrobilurinas (Tabela 1).

A atividade da redutase do nitrato em folhas de plantas tratadas com azoxistrobina e água ajustouse ao modelo quadrático $\left(\mathrm{R}^{2}=0,91\right.$ e $\mathrm{R}^{2}=0,83$, respectivamente), indicando baixa atividade logo após repicagem, mais alta posteriormente, enquanto que, em plantas tratadas com piraclostrobina o ajuste foi linear crescente $\left(\mathrm{R}^{2}=0,98\right)$, indicando aumento na atividade proporcional ao tempo e número de aplicações do fungicida (Figura 1). Houve pouca diferença na atividade da enzima entre plantas tratadas com azoxistrobina e plantas não-tratadas (água). Adicionalmente, aos 46 dias após o início da aplicação dos tratamentos, o teor de aminoácidos livres também foi mais elevado em plantas tratadas com piraclostrobina em comparação com aos demais tratamentos (Figura 2). 
Tabela 1. Altura (ALT), diâmetro do pseudocaule (D), número de folhas (NF), área foliar (AF), massa da matéria seca da raiz (MSR), massa da matéria seca da parta aérea (MSPA), teor de clorofila $a(\mathrm{Cl} a)$ e $b(\mathrm{Cl} b)$ e carotenóides (Car) e nitrogênio total ( $\mathrm{N}$ total) em mudas de bananeira cultivar Grand Naine aos 84 dias após a repicagem após tratamento com água, azoxistrobina e piraclostrobina.

\begin{tabular}{lccc}
\hline & Água & $\begin{array}{c}\text { Azoxistrobina } \\
\left(100 \mathrm{~g} \mathrm{i}^{\mathrm{a} . \mathrm{h}^{-1}}\right)\end{array}$ & $\begin{array}{c}\text { Piraclostrobina } \\
\left(100 \mathrm{~g} \mathrm{i}^{\mathrm{a} . \mathrm{ha}^{-1}}\right)\end{array}$ \\
\hline $\mathrm{ALT}(\mathrm{cm})$ & $* 51,15 \mathrm{c}$ & $59,63 \mathrm{~b}$ & $68,18 \mathrm{a}$ \\
$\mathrm{D}(\mathrm{cm})$ & $2,39 \mathrm{c}$ & $2,74 \mathrm{~b}$ & $3,01 \mathrm{a}$ \\
$\mathrm{NF}$ & $9,12 \mathrm{a}$ & $9,72 \mathrm{a}$ & $9,65 \mathrm{a}$ \\
$\mathrm{AF}\left(\mathrm{dm}^{2}\right)$ & $18,15 \mathrm{~b}$ & $19,28 \mathrm{~b}$ & $23,01 \mathrm{a}$ \\
$\mathrm{MSR}(\mathrm{g})$ & $9,63 \mathrm{a}$ & $9,26 \mathrm{a}$ & $10,02 \mathrm{a}$ \\
$\mathrm{MSPA}(\mathrm{g})$ & $18,63 \mathrm{c}$ & $23,15 \mathrm{~b}$ & $29,36 \mathrm{a}$ \\
$\mathrm{Cl} a\left(\mu \mathrm{g} \mathrm{g}^{-1} \mathrm{MF}\right)$ & $0,85 \mathrm{~b}$ & $0,83 \mathrm{~b}$ & $0,95 \mathrm{a}$ \\
$\mathrm{Cl} b\left(\mu \mathrm{g} \mathrm{g}^{-1} \mathrm{MF}\right)$ & $0,23 \mathrm{a}$ & $0,27 \mathrm{a}$ & $0,30 \mathrm{a}$ \\
$\mathrm{Car}\left(\mu \mathrm{g} \mathrm{g}^{-1} \mathrm{MF}\right)$ & $0,52 \mathrm{~ns}$ & $0,54 \mathrm{~ns}$ & $0,555^{\mathrm{ns}}$ \\
$\mathrm{N}$ total $\left(\mathrm{g} \mathrm{kg}^{-1}\right)$ & $28,7 \mathrm{~b}$ & $29,5 \mathrm{~b}$ & $39,3 \mathrm{a}$ \\
\hline
\end{tabular}

*Valores representam a média de dois experimentos: médias seguidas da mesma letra na linha não diferem entre si, a $5 \%$ de probabilidade pelo teste Tukey.

Figura 1. Atividade da redutase do nitrato in vivo em folhas de mudas de bananeira tratadas com água, azoxistrobina $\left(100 \mathrm{~g}\right.$ i. a. ha $\left.{ }^{-1}\right)$ e piraclostrobina $\left(100 \mathrm{~g}\right.$ i. a. ha $\left.{ }^{-1}\right)$, aos 5, 30, 45, 60, 75 dias após a aplicação dos tratamentos. As setas representam o tempo em dias em que foi feita a determinação da atividade. Valores representam a média de dois experimentos: significativo a $1 * *$ e $5 * \%$ de probabilidade pelo teste t.

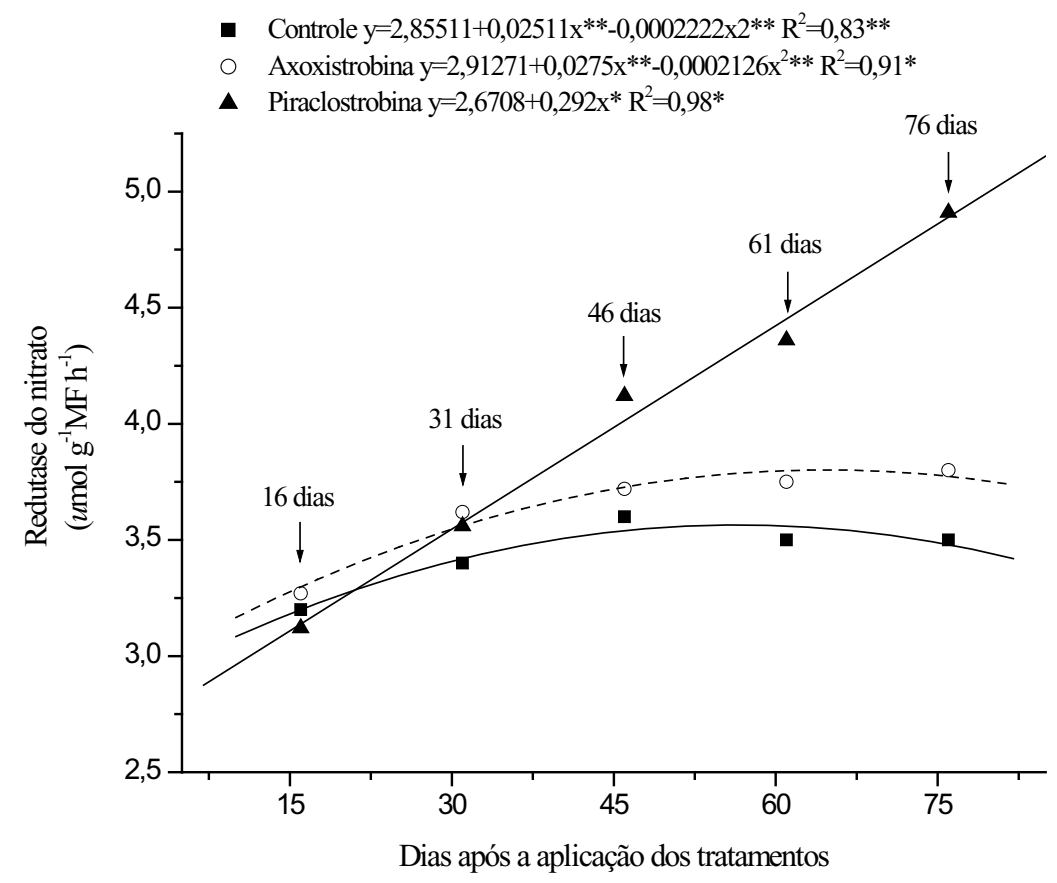


Figura 2. Teor de aminoácidos livres totais em folhas de mudas de bananeira tratadas com água, azoxistrobina (100 g i. a. ha $\left.{ }^{-1}\right)$ e piraclostrobina ( $100 \mathrm{~g}$ i. a. ha $\left.{ }^{-1}\right)$, aos 5, 30, 45, 60, 75 dias após a aplicação dos tratamentos. As setas representam o tempo em dias em que foi feita a determinação da atividade. Valores representam a média de dois experimentos: significativo a $1 * *$ e $5 * \%$ de probabilidade pelo teste $t$.

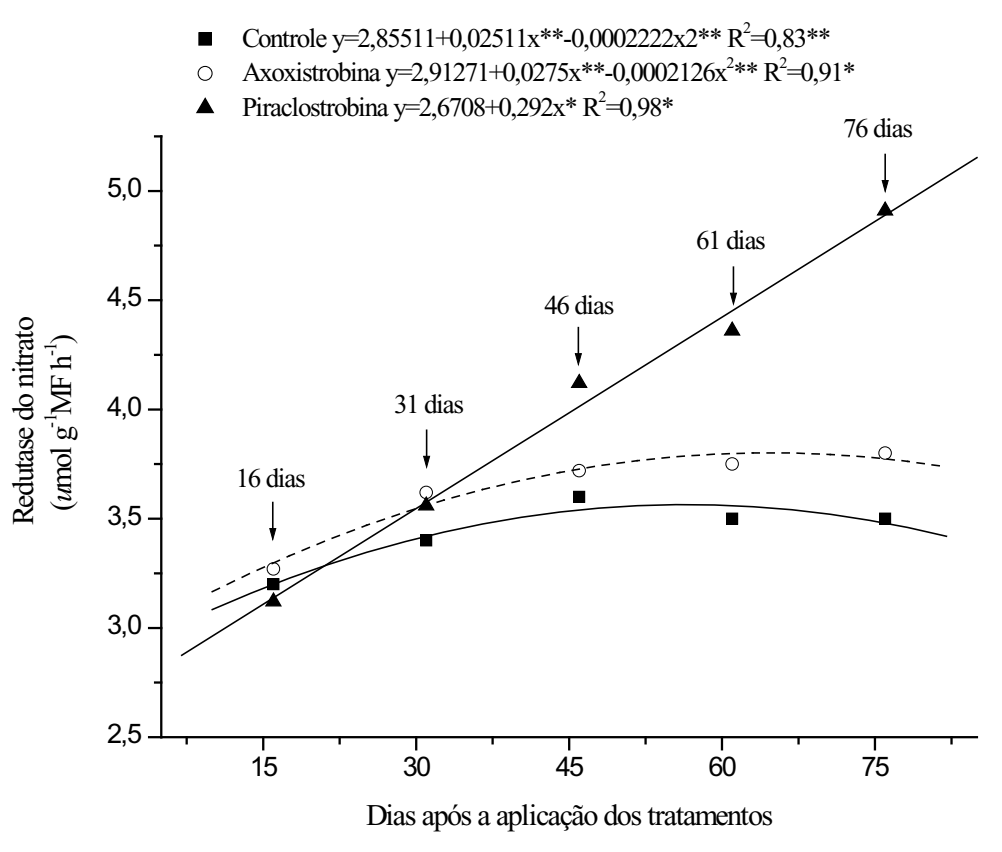

Estrobilurinas inibem o transporte de elétrons nas mitocôndrias entre o citocromo $b$ e citocromo $c_{1}$ (Complexo III), interferindo desta forma na síntese de ATP e bloqueando o abastecimento de energia das células do fungo (AZEVEDO, 2001). Do mesmo modo, interferem transitoriamente no transporte de elétrons da mitocôndria da célula vegetal e reduzem a taxa de respiração, como conseqüência promovem melhor utilização do $\mathrm{CO}_{2}$ e redução de gasto de energia, resultando em maior acúmulo de carboidratos pelo aumento da fotossíntese líquida (OLIVEIRA, 2005). Assim sendo, baseado no mecanismo de ação das estrubilurinas, apesar do maior acúmulo de carbono na parte aérea das plantas de bananeiras tratadas com azoxistrobina, que são constituídas basicamente de folhas, não houve diferença significativa nos valores da área foliar, teores de pigmentos fotossintéticos, teor de nitrogênio total, atividade da redutase do nitrato
(Figura 1) e de aminoácidos livres totais (Figura 2), em relação a plantas tratadas apenas com água. Dessa forma, o maior ganho de carbono pode ser atribuído apenas a um aumento na fotossíntese líquida, devido a redução na taxa respiratória. Em plantas tratadas com piraclostrobina, o ganho de carbono também pode ser atribuído ao aumento da área foliar e do teor de clorofila $a$. Piraclostrobina promoveu um aumento no teor de clorofila da folha, redução na respiração e aumento da fotossíntese líquida em plantas de soja (DOURADO NETO; OLIVEIRA, 2005; RODRIGUES, 2009) e milho (DOURADO NETO; OLIVEIRA, 2005).

A redutase do nitrato é uma enzima chave para o metabolismo do nitrogênio, visto que catalisa o primeiro passo que culmina no processo de assimilação do nitrato, forma de nitrogênio que é predominante no solo. Assim sendo, a maior atividade da redutase do nitrato no tecido foliar 
promovida pela piraclostrobina (Figura 1), juntamente com valores mais altos de aminoácidos livres totais (Figura 2) e de nitrogênio total (Tabela 1), pode indicar, em primeiro momento, uma maior assimilação do nitrogênio. Isto justifica os teores mais altos de compostos nitrogenados relacionados com assimilação de carbono, tais como pigmentos fotossintéticos, caso da clorofila a (Tabela 1), bem como de proteínas, conforme observado por Mercer e Ruddock (1998), resultando em maior crescimento das mudas de bananeira. Este aumento da atividade da redutase do nitrato em plantas tratadas com piraclostrobina, também observado em outros trabalhos (AMARO, 2011; FAGAN et al., 2010; LOPES, 2011; RODRIGUES, 2009), pode ser uma consequência da demanda de nitrogênio, gerada pelo incremento no ganho de carbono, ou do decréscimo no $\mathrm{pH}$ citosólico, devido à inibição parcial do transporte de elétrons da mitocôndria (GLAAB; KAISER, 1999).

Em condições de campo, a maior atividade da enzima poderia promover maior produtividade. Em milho e soja também foram observados aumentos na atividade (KÖEHLE et al., 2003; DOURADO NETO; OLIVEIRA, 2005) e na ativação da enzima redutase do nitrato (GLAAB; KAISER, 1999), além de acúmulo de nitrato no tecido foliar, durante o primeiro período noturno após a aplicação da estrobilurina (KÖEHLE et al., 2003). Diferente dos resultados obtidos no presente estudo, plantas de feijão tratadas com piraclostrobina não apresentaram teores mais elevados de clorofila nem de área foliar, porém maiores valores na taxa de crescimento absoluto da área foliar, indicando expansão mais rápida do tecido foliar. Isso resultou em maior período de duração da área foliar, o que provavelmente contribuiu para maior produtividade, quando comparado com plantas tratadas com azoxistrobina (KOZLOWSKI et al., 2009).

Os resultados obtidos no presente estudo não pretendem promover o uso indiscriminado das estrobilurinas como fungicida, nem tampouco como indutor de resistência ou regulador de crescimento vegetal, mas indicá-las como parte da estratégia de manejo anti-resistência de populações do fungo Mychosphaerella fijiensis, quando aplicadas em alternância com os demais fungicidas registrados para a cultura que, aliada a prática cultural de adubação nitrogenada, pode resultar em aumento da produtividade.

\section{Conclusões}

As estrobilurinas (azoxystrobina e pyraclostrobina) afetam a fisiologia de mudas de bananeira micropropagadas, com destaque para piraclostrobina que apresenta efeito mais pronunciado;

Azostrobina e piraclostrobina promovem o crescimento das mudas em altura e diâmetro do pseudocaule, além de maior acúmulo de matéria seca da parte aérea;

Piraclostrobina promove incremento na área foliar, atividade da redutase do nitrato in vivo, teor de clorofila e de nitrogênio total foliar.

\section{Referências}

AMARO, A. C. E. Efeitos fisiológicos de fungicidas no desenvolvimento de plantas de pepino japonês enxertadas e não enxertadas, cultivadas em ambiente protegido. 2011. Dissertação (Mestrado em Agronomia) - Universidade Estadual Paulista. Faculdade de Ciências Agronômicas, Botucatu.

AUGUSTI, G. R.; STEFANELO, M. S.; PÉS, M. P.; SARI, B. G.; RODRIGUES, J. S.; COSTA, I. F. D. da. Aumento do teor de nitrito e da produtividade da soja (Glycine max) com a aplicação de fungicidas. In: REUNIÃO DE PESQUISA DE SOJA DA REGIÃO SUL, 38., 2010, Cruz Alta, RS. Atas e Resumos.... Cruz Alta: FUNDACEP FECOTRIGO, 2010, v. 1, p. 155-158.

AZEVEDO, L. A. S. Proteção integrada de plantas com fungicidas: teoria, prática e manejo. São Paulo: Syngenta, 2001. 230 p.

BALARDIN, R. S.; SILVA, F. D. L. da; DEBONA, D.; CORTE, G. D.; FAVERA, D. D.; TORMEN, N. R. Tratamento de sementes com fungicidas e inseticidas 
como redutores dos efeitos do estresse hídrico em plantas de soja. Ciência Rural, Santa Maria, v. 41, n. 7, p. 11201126, 2011.

BERTELSEN, J. R.; NEERGAARD, E. de; SMEDEGAARD-PETERSEN, V. Fungicida effects azoxystrobin and epoxiconazole on phyllosphere fungi, senescence and yield oh winter wheat. Plant Pathology, Oxford, v. 50, n. 2, p. 190-205, 2001.

BIELESKI, L. R.; TURNER, N. A. Separation and estimation of amino acids in crude plant extracts by thinlayer electrophoresis and chromatography. Analytical Biochemistry, New York, v. 17, p. 278-293, 1966.

BOLLMARK, M.; ELIASSON, L. Ethylene accelerates the breakdown of cytokinins and thereby stimulates rooting in Norway spruce hypocotyl cuttings. Physiologia Plantarum, Copenhagen, v. 80, n. 4, p. 527-533, 1990.

CORDEIRO, Z. J. M.; MATOS A. P. de; MEISSNER FILHO, P. E. Doenças e métodos de controle. In: BORGES, A. L.; SOUZA, L. da S. O cultivo da bananeira. Cruz das Almas: Embrapa Mandioca e Fruticultura Tropical, 2004, p. 146-182.

DOURADO NETO, D.; OLIVEIRA, R. F.; BEGLIOMINI, E.; RODRIGUES, M. A. T. F500 em soja e milho: efeitos fisiológicos comprovados. Atualidades Agrícolas BASF S.A., p. 12-16, dez. 2005.

FAGAN, E. B.; DOURADO NETO, D.; VIVIAN, R.; FRANCO, R. B.; YEDA, M. P.; MASSIGNAM, L. F.; OLIVEIRA, R. F. de; MARTINS, K. V. Efeito da aplicação de piraclostrobina na taxa fotossintética, respiração, atividade da enzima nitrato redutase e produtividade de grãos de soja. Bragantia, Campinas, v. 69, n. 4, p. 771-777, 2010.

GLAAB, J.; KAISER, W. M. Increased nitrate reductase activity in leaf tissues after application of the fungicide Kresoxim-methyl. Planta, Berlin, v. 207, n. 3, p. 442448, 1999.

GROSSMAN, K.; RETZLAFF, G. Bioregulatory effects of the fungicidal strobirulin kresoxim-methyl in wheat (Triticum aestivum). Pesticide Science, Oxford, v. 50, p. 11-20, 1997.

HAGEMAN, R. H.; REED, A. J. Nitrate reductase from higher plants. In: PIETRO, A. S. Methods in enzymology. San Diego: Academic Press, 1980. v. 60, p. 270-280.

HISCOX, J. D.; ISRAELSTAM, G. F. A method for the extraction of chlorophyll from leaf tissue without maceration. Canadian Journal of Botany, Otawa, v. 57, n. 12, p. 1332-1334, 1979.

INSTITUTO BRASILEIRO DE GEOGRAFIA E ESTATÍSTICA - IBGE. Levantamento sistemático da produção agrícola: pesquisa mensal de previsão e acompanhamento das safras agrícolas no ano civil. Rio de Janeiro: IBGE, v. 4, n. 8, p. 1-82, 2011.

JAWORSKI, E. G. Nitrate reductase assay in intact plant tissues. Biochemical and Biophysical Research Communications, Orlando, v. 43, n. 6, p. 1274-1279, 1971.

JONES, D. R.; BRYSON, R. J. Physiological effects of strobilurins and plant activators in relation to yield of winter wheat. London: Oxford University Press, 1998. (Home Grown cereals Authority Project Report, n. 164).

KÖEHLE, H.; GROSSMANN, K.; JABS, T.; GERHARD, M.; KAISER, W.; GLAAB, J.; CONRATH, U.; SEEHAUS, K.; HERMS, S. Physiological effects of the strobilurin fungicide F 500 on plants. In: DEHNE, H. W.; GISI, U.; KUCK, K. H.; RUSSELL, P. E.; LYR, H. (Ed.). Modern fungicides and antifungal compounds III. Andover: AgroConcept, 2002. p. 61-74.

KOZLOWSKI, L. A.; SIMÕES, D. F. M.; SOUZA, C. D. de; TENTRO, M. Efeito fisiológico de estrobilurina F500® no crescimento e rendimento do feijoeiro Revista Acadêmica: Ciência Agrária e Ambientais, Curitiba, v. 7, n. 1, p. 41-54, 2009.

LEA, P. J. Primary nitrogen metabolism. In: DAY, P. M.; HARBORN, J. B. (Ed.). Plant biochemistry. New York: Academic Press, 1997. cap. 7, p. 273-313.

LOPES, E. C. P. Efeitos fisiológicos de fungicidas no crescimento, produtividade e pós-colheita de batata (Solanum tuberosum L.). 2011. Dissertação (Mestrado em Agronomia) - Universidade Estadual do CentroOeste, Guarapuava.

MERCER, P. C.; RUDDOCK, A. Evaluation of azoxystrobin and range of conventional fungicides on yield, Septoria tritici and senescence in winter wheat. Annals of Applied Biology, v. 132, p. 24-25, 1998. Suplemento.

MORAES, W. S.; FERRARI, J. T.; FUKUDA, E.; MENDONÇA, J. C. Situação atual da Sigatoka Negra no Estado de São Paulo, Pariquera-Açu, SP, 2006. In: SIMPÓSIO DE MANEJO ADEQUADO DA SIGATOKA NEGRA NA CULTURA DA BANANA, 1 , 2006, Pariquera-Açu, SP. Anais... Pariquera-Açu: Pólo Regional do Vale do Ribeira, 2006. v. 1, p. 22-41.

NÓBREGA, J. P. R.; PEREIRA, W. E.; DIAS, T. J.; RAPOSO, R. W. C.; ARAÚJO, R. da C.; OLIVEIRA, F. A de. Poda do pseudocaule e doses de nitrogênio e boro na produção de mudas de bananeira 'Pacovan'. Semina: Ciências Agrárias, Londrina, v. 31, p. 1205-1218, 2010. Suplemento 1. 
OLIVEIRA, R. F. de. Efeito fisiológico do F 500 na planta de soja e milho. Atualidades Agrícolas - BASF, São Paulo, 2005. p. 9-11.

RODRIGUES, M. A. T. Avaliação do efeito fisiológico do uso de fungicidas na cultura da soja. 2009. Tese (Doutorado em Ciências) - Escola Superior de Agricultura. Universidade de São Paulo, Piracicaba.

TSUMANUMA, G. M.; CARVALHO, S. J. P. de; FANCELLI, A. L.; BERNARDES, M. S.; RODRIGUES, M. A. T.; BEGLIOMINI, E. Revista Ceres, Viçosa, v. 57, n. 6, p. 742-750, 2010.

VAZAMI, B. K.; LIMA, J. D.; MORAES, W. da SILVA; SILVA JUNIOR, A. C. Otimização das condições de ensaio da redutase do nitrato em folha de mudas de bananeira 'Grand Nine'. In: CONGRESSO DE INICIAÇÃO CIENTIFICA DA UNESP, 9., 2007, Ilha Solteira. Anais... São Paulo: PROPE UNESP, 2007. p. 44-47.
VENÂNCIO, W. S.; RODRIGUES, M. A. T.; BEGLIOMINI, E.; SOUZA, N. L. de. Efeitos fisiológicos de fungicidas do grupo das estrobilurinas sobre plantas. Publicatio UEPG Ciências Exatas e da Terra, Ponta Grossa, v. 9, n. 3, p. 59-68, 2003.

WELLBURN, A. R. The spectral determination of chlorophylls $a$ and $b$, as well as total carotenoids, using various solvents with spectrophotometers of different resolution. Journal of Plant Physiology, Minneapolis, v. 144, n. 3, p. 307-313, 1994.

WU, Y-X.; VON TIEDEMANN, A. Physiological effects of azoxystrobin and epoxiconazole on senescence and the oxidative status of wheat. Pesticide Biochemistry and Physiology, San Diego, v. 71, n. 1, p. 1-10, 2001.

YEMM, E. W.; COCKING, E. C. The determination of amino acids with ninhydrin. Analyst, London, v. 80, p. 209-213, 1955.

YPEMA, H. L.; GOLD, R. E. Kresoxim-methyl: modification of a naturally occurring compound to produce a new fungicide. Plant Disease, Saint Paul, v. 83, n. 1, p. 4-19, 1999. 
